\title{
Neodesenvolvimentismo e conflitos sociais: o caso da Hidrelétrica de Belo Monte
}

\section{Neo-developmentism and social conflicts: the case of Belo Monte Dam}

Sérgio Roberto Moraes Corrêa - Professor da Universidade do Estado do Pará, vinculado ao Departamento de Filosofia e Ciências Sociais. Doutor em Ciências Sociais pela Universidade Federal de Campina Grande (PPGCS-UFCG). E-mail: sergiorcm2001@ yahoo.com.br

\section{Resumo}

O texto trata da temática do neodesenvolvimentismo no Brasil na atualidade, com foco na particularidade amazônica à luz dos conflitos sociais. Para isso, toma como objeto de estudo as lutas de resistência do Movimento Xingu Vivo Para Sempre frente à Hidrelétrica de Belo Monte. Esse texto é parte da tese de doutorado realizada no Programa de PósGraduação em Ciências Sociais da UFCG. Nessa pesquisa, foi possível identificar que Belo Monte é a expressão, por meio do PAC, da expansão da fronteira hidrelétrica como movimento de territorialização da dinâmica de acumulação do capital sobre a Amazônia sob forte influência do Estado, em parceria com grandes grupos privados. Esse padrão de desenvolvimento é marcado, contudo, por fortes contradições e conflitos, sendo as lutas e resistências de movimentos sociais reveladoras de outras dinâmicas sociais, que, nos termos de Boaventura Santos, ajudam a revelar outras representações e experiências da Amazônia e do Brasil.

\section{Palavras-chave}

Neodesenvolvimentismo. Amazônia. Hidrelétrica de Belo Monte. Conflitos Sociais. Movimento Xingu Vivo Para Sempre.

\begin{abstract}
The text deals with the neo-developmentism the theme in Brazil today, focusing on Amazon particularity in the light of social conflicts. To do this, take as object of study the resistance struggles of the Xingu Vivo Movement Forever front of the Belo Monte Hydroelectric Plant. This text is part of the doctoral thesis carried out at the Graduate in Social Sciences UFCG Program. In this research, it was possible to identify that Belo Monte is the expression, through the CAP, the expansion of hydroelectric border and territorial movement of the dynamics of capital accumulation on Amazon under the strong influence of the state in partnership with private groups. This pattern of development is marked, however, by strong contradictions and conflicts, and the struggles and resistance of revealing social movements of other social dynamics, which, in terms of Boaventura Santos, help reveal other representations and experiences of the Amazon and Brazil.
\end{abstract}

\section{Keywords}

Neo- developmentism. Amazon. Hydroelectric Belo Monte. Social conflicts. Xingu Alive Forever Movement. 


\section{INTRODUÇÃO}

O governo federal, por meio do Programa de Aceleração do Crescimento (PAC), retomou uma série de Grandes Projetos na Amazônia, que visam ampliar e alargar a infraestrutura do país para levar a cabo seu processo de integração e desenvolvimento com crescimento econômico interno, assim como fortalecer sua inserção internacional, em especial a integração Sul-Americana, como parte desse processo de globalização de mercados.

Entre os diversos projetos em curso para região, sobressai-se o megaempreendimento de "Aproveitamento Hidrelétrico de Belo Monte", no sudoeste do Estado do Pará. Esse empreendimento, contudo, tem sido alvo de diversas polêmicas (contra e a favor) e gerado bastante tensões e conflitos socioambientais. Esse quadro sugere levantar as seguintes questões: as matrizes prático-discursivas oficiais inscrevem que concepção de desenvolvimento na Amazônia por meio dos grandes empreendimen tos hidrelétricos do PAC, como Belo Monte? O que os povos e movimentos sociais que lutam contra esse empreendimento têm a revelar sobre esse modelo de desenvolvimento para a região? Se ajustarmos a lente para realçar as dimensões dos conflitos sociais, a partir dessas lutas e resistências desses segmentos sociais, o que isso pode suscitar de elementos para interpretar e debater o tema do desenvolvimento na região e no país? O presente texto está estruturado em três tópicos, além desta introdução e da conclusão.

\section{O NEODESENVOLVIMENTISMO EM DEBATE}

Identificamos um revigoramento do tema do desenvolvimento, em particular do neodesenvolvimentismo, e desse debate na agenda de pesquisa das Ciências Sociais/Humanas, de formuladores de Políticas Públicas e de diversos agentes sociais da sociedade civil, exprimindo profundas tensões e conflitos em torno de concepções e projetos em disputa na sociedade. Isso sugere e exige uma análise desse processo em curso, considerando aqui as dinâmicas e configurações particulares do Brasil, em especial da Amazônia, relacionadas à dinâmica mais ampla e complexa Regional e Global, dominada pela dinâmica capitalista. Apresentamos resumidamente algumas ideias acerca desse tema.

Uma dessas abordagens é o Novo Desenvolvimentismo. Para defensores dessa perspectiva, como o economista Bresser-Pereira (2003, 2006), o Brasil precisa de um novo caminho, com vistas a construir de forma redefinida uma estratégia nacional de desenvolvimento, visto seu contexto atual diferente, uma nova realidade, que aponta 
e enfrenta novos desafios. Para esse autor, essa perspectiva se apresenta como um contraponto ao "antigo desenvolvimentismo" e à "ortodoxia convencional" ou agenda neoliberal que entraram em crise (BRESSER-PEREIRA, 2006).

Sob esse ângulo, o novo desenvolvimentismo é entendido como um "terceiro discurso" e o "conjunto de diagnósticos e ideias", que servem de base e orientação para a formulação da estratégia nacional de desenvolvimento de cada Estado-Nação, reassumindo este, junto com o mercado, lugar protagônico nesse processo. Nesse sentido, ele se expressa como "um conjunto de propostas de reformas institucionais e de políticas econômicas, por meio das quais as nações de desenvolvimento médio buscam, no início do século XXI, alcançar os países desenvolvidos". Ademais, defende a permanência das políticas públicas e flexibilização das relações de trabalho (BRESSER-PEREIRA, 2006, p. 12-19).

Ao polemizar essa retomada do debate desenvolvimentista e suas variações, Fiori (2011) assume uma posição crítica em relação ao chamado "novo desenvolvimentismo", identificando-o como uma tentativa de "terceira via". O referido autor sustenta que os defensores desse neodesenvolvimentismo incorrem nos mesmos erros teóricos do passado e propõem "um conjunto de medidas ainda mais vagas e gelatinosas do que já havia sido a ideologia nacionaldesenvolvimentista dos anos 50". Para ele, "trata-se de um pastiche de propostas macroeconômicas absolutamente ecléticas". Ao problematizar o papel do Estado abordado por eles, identifica que "a questão central do poder e dos interesses contraditórios das classes e das nações" é deixada de lado, demonstrando sua fragilidade analítica com consequência política (FIORI, 2011, p. 2). Em outros dois artigos seus, Fiori (2012) desfere fortes críticas às correntes mais à esquerda desse debate, em especial à chamada Escola Campineira. No primeiro artigo, ele acusa essa corrente de esquerda de um estreitamento de seu "horizonte utópico", transformando-se numa "ideologia tecnocrática, sem mais nenhuma capacidade de mobilização social” (FIORI, 2012, p. 2).

Contrapondo as críticas de Fiori, Carneiro (2012) rebate sustentando a existência de pelo menos duas vertentes nesse debate atual. Uma delas é o já citado novo desenvolvimentismo, cujo centro estaria na Fundação Getúlio Vargas (FGV-SP), que "privilegia as dimensões macro das políticas econômicas e subordina a elas as políticas de desenvolvimento dando maior peso ao papel do mercado (CARNEIRO, 2012, p. 3). No outro lado desse campo, situa-se o social-desenvolvimentismo, com origem na Unicamp e na UFRJ, assumindo o social como eixo estruturante de desenvolvimento e isto se daria pela centralidade do mercado interno por meio da ampliação do consumo de bens públicos e privados - pelas massas. Para essa vertente, propõe-se "a subordinação das 
políticas macroeconômicas às de desenvolvimento e o maior peso do Estado. O desenvolvimento das forças produtivas seria, nesse caso, um meio para atingir o objetivo almejado" (CARNEIRO, 2012, p. 3).

Em sua abordagem, Cepêda (2012), ao diferenciar o novo-desenvolvimentismo do velho, identifica uma mudança na questão nuclear, que a aproxima desse campo do "social-desenvolvimentismo". Para ela, o "novo-desenvolvimentismo, ao contrário, apoia-se no processo de inclusão social, colocando redistribuição e equidade em posição prioritária", acrescentando que a "questão nacional que cimenta o novo-desenvolvimentismo, presente nas políticas públicas federais da última década e em seu projeto de sustentação (PAC I e PAC II), apoia-se no diagnóstico da exclusão social como eixo do problema atual" (CEPÊDA, 2012, p, 84). Cercando a problemática por esse ângulo, a autora reconhece a combinação de "políticas de crescimento com políticas de distribuição" no novodesenvolvimentismo apresentado por Sicsú et al. (2007), mas destaca o lugar que a segunda vem ganhando na agenda do governo, o que possibilita ajustar o foco para o protagonismo do Estado e da dimensão social (CEPÊDA, 2012, p, 84). Nessa perspectiva, o Estado é reposicionado como protagonista da ação política nessa agenda, mas de maneira redefinida, assumindo a dimensão social - a política distributiva - lugar de destaque no processo de democratização, por meio de políticas públicas sociais com forte papel do Estado. Ao colocar nesses termos, a autora difere sua abordagem, sobretudo, da de Bresser-Pereira, centrado mais na macroeconomia e no mercado.

Aorefletirsobreesse "retorno" ou a "reencarnação" do desenvolvimentismo na atualidade, em particular considerando o "campo da esquerda", Ridenti (20092010; 2009) destaca a necessidade de um "estranhamento" quanto a tal retorno. Entende que este não é uma volta a este (embora considere relevante esse debate anterior), mas um retorno modificado com renovações de pensamento e de ação política no campo de esquerda. Uma primeira aproximação de resposta às suas questões se expressaria nas crises do modelo neoliberal e do pensamento das esquerdas: "com as dificuldades de organização dos despossuídos trazem de novo propostas (diferenciadas) na atuação do Estado para a retomada do desenvolvimento nos marcos do capitalismo" (RIDENTI, 2009, p. 7).

Esse autor chama a atenção para o cuidado de não se esquecer de um debate clássico de (auto) crítica e de crítica ao desenvolvimentismo, questionando: a quem serve o desenvolvimento? A que grupos e classes sociais?; e das dimensões emergentes que passam a ocupar lugar de destaque na agenda acadêmica e política da sociedade, como as questões ambiental e da sustentabilidade do desenvolvimento (RIDENTI, 2009, p. 7). 
Se a crise de hegemonia da agenda neoliberal e a crise de alternativas à esquerda, por um lado, como bem destacou Ridenti, constituem-se como fatores relevantes para a retomada desse debate "desenvolvimentista" sob outras variantes na atualidade; por outro lado, isso não implica afirmar que a agenda neodesenvolvimentista tenha produzido uma ruptura drástica com o receituário anterior (neoliberal), implantando algo genuinamente novo. $\mathrm{O}$ neodesenvolvimentismo está caracterizado por marcantes continuidades com a política econômica anterior, dada a acentuação que o mercado (macroeconomia) vem assumindo em algumas abordagens e o esvaziamento da relação de poder, mesmo que o Estado seja colocado em suposto "equilíbrio" com ele e o crescimento se combine com "equidade social".

É possível, contudo, também, identificar sinais de inflexão, que inscrevem o reposicionamento do Estado e maior ênfase na dimensão social, demarcando a política como relevante no combate à exclusão social e à desigualdade nos marcos do desenvolvimento do capitalismo depedente, reforçando a dinâmica hegemônica deste e sua variabilidade, em particular no continente latinoamericano. Nesses termos, o neodesenvolvimentismo vem se constituindo num campo de debate em processo de formação, marcado por perspectivas e ângulos diferentes e conflitantes. Nesse quadro traçado do neodesenvolvimentismo, o lugar das relações de poder entre as classes e grupos sociais dominantes e subalternos é subsumida, assim como a questão ambiental não ocupa lugar de destaque nessa agenda.

\section{O PAC COMO SÍMBOLO DA AGENDA NEODESENVOLVI- MENTISTA: que lugar é reservado à Amazônia?}

Um exemplo dessa reposição do Estado brasileiro se expressa no Programa de Aceleração do Crescimento (PAC I 2007 a 2010) - lançado pelo governo federal em janeiro de 2007. Esse Programa prioriza investimentos em infraestrutura e medidas institucionais, objetivando alavancar o crescimento econômico do país, por meio de investimento público e do estímulo ao investimento privado (BRASIL, 2007). Nesse documento oficial, concebe-se e defende-se o PAC como um Programa de Desenvolvimento (BRASIL, 2007, p. 2).

Ao informar seus "fundamentos econômicos", ele diz estar calçado num tripé: "estabilidade monetária", "responsabilidade fiscal" e "baixa vulnerabilidade externa". As suas "medidas" estão organizadas em "cinco blocos": 1) Investimento em Infra-Estrutura; 2) Estímulo ao Crédito e ao Financiamento; 3) Melhora do Ambiente de Investimento; 4) Desoneração e Aperfeiçoamento do Sistema Tributário e 5) Medidas 
Fiscais de Longo Prazo (BRASIL, 2007, p. 4). No Bloco I, o governo objetivou aumentar o investimento em infraestrutura para "eliminar os principais gargalos que podem restringir o crescimento da economia; reduzir custos e aumentar a produtividade das empresas; estimular o aumento do investimento privado; e reduzir as desigualdades regionais" (BRASIL, 2007, p. 6). De um total de mais de 500,3 bilhões de Reais para essa área, só o investimento em energia foi de 274,8 bilhões de Reais, mais de 50\%, ao passo que em "infraestrutura social" foi de 170 , 8 bilhões. Ao defender a Melhora do Ambiente do Investimento, o governo federal entende que "o aumento do investimento também depende de um ambiente regulatório e de negócios adequados” (BRASIL, 2007, p. 18).

Quando considerada a distribuição dos recursos do PAC entre as regiões brasileiras, tem-se o seguinte desenho distributivo: A Região Sudeste concentra a maior parcela dos investimentos, $\mathrm{R} \$ 243,6$ bilhões, 48,34\% dos recursos; a Região Nordeste vem em segundo com R \$115,6 bilhões, 22,94\%; a Região Norte totaliza $\mathrm{R} \$ 62,9$ bilhões, 12,48\%; as regiões Sul e Centro-Oeste totalizam conjuntamente 16,24\% dos investimentos. Se considerada a Amazônia Legal, percebe-se que esse investimento se eleva para $\mathrm{R} \$ 83,6$ bilhões, distribuídos assim: Acre $\mathrm{R} \$ 1,3$ bilhão (1,56\%); Amapá R \$ 3,2 bilhões (2,83\%); Amazonas R \$ 8,7 bilhões (10,41\%); Maranhão R \$ 9,1 bilhões (10,89\%); Mato Grosso R\$11, 6 bilhões (13,88\%); Pará $\mathrm{R} \$ 12,7$ bilhões (15,19\%); Rondônia R \$ 17, 9 bilhões (21,41\%); Roraima R $\$ 0$, 6 bilhões $(0,72 \%)$; Tocantins R $\$ 18,5$ bilhões (22,13\%). Esse valor totaliza pouco mais de um terço dos investimentos que foram destinados ao Sudeste.

A prioridade de investimento, como estratégia de desenvolvimento para a região, se concentrou na infraestrutura energética, que recebeu 58,66\% dos recursos. As áreas de logística e infraestrutura social e urbana ficaram, respectivamente, com 25,93\% e 15,41\% dos recursos. Contudo, é importante considerar que essa projeção de investimentos se alterou. No caso do Estado do Pará, esse valor foi elevado em 2009 e chegou a 20,3 bilhões. Foram distribuídos 15,18 bilhões (entre os anos de 2007 e 2010) nos eixos de infra-estrutura e R\$ 5,74 bilhões (para o período pós-2010), concentrado no setor energético.

No Balanço do PAC 2007-2010, foi apresentado um conjunto de resultados, focando sobretudo na taxa de crescimento do PIB, que alcançou uma média de $5 \%$. Ademais, esse documento enfatiza o resultado oriundo do investimento em infraestrutura no país e na geração de emprego e melhoria da renda: ampliação e aumento de consumo no mercado interno associada à "expansão acentuada do crédito" e ao reposicionamento do BNDES; aumento expressivo das reservas internacionais e queda da dívida externa liquida. Isso tudo conforme a garantia da estabilidade econômica e da política fiscal (BRASIL, 2010b). 
Com o slogan O Brasil vai continuar crescendo, o PAC II (2011-2014) inicia fazendo alusão ao "legado do PAC I", enfatizando que "o país cresceu em 2007, 2008 e crescerá em 2010 mais do que a meta de 5\% prevista no PAC I”. Ao informar sobre o aumento do emprego em infra-estrutura no período de dezembro de 2006 a dezembro de 2009, esse documento enfatiza: em rodovias e ferrovias, o crescimento foi de $76 \%$, seis vezes mais do que a média; em saneamento foi de $64 \%$, cinco vez mais do que a média; em construção de edifícios foi de $41 \%$, três vezes mais do que a média. Além disso, enfatiza a "maior parceria com Estados e municípios" e a "ampliação das parcerias entre o setor público e o investidor privado" (BRASIL, 2012a). Nesse sentido, argumenta: "Assim como na primeira etapa do Programa, o principal objetivo é aumentar o ritmo da economia, combinando esse aumento com geração de empregos, distribuição de renda e inclusão social" (BRASIL, 2012b, p. 1-2).

Do montante de investimento do PAC II, dois terços se dirigem ao PAC Energia, ampliando bastante o investimento em relação ao PAC I.

Tabela 1 - PAC II- investimento em energia (em R\$ bilhões)

\begin{tabular}{l|c|c|r}
\hline \multicolumn{1}{c|}{ EIXOS } & $2011-2014$ & PÓS 2014 & \multicolumn{1}{c}{ TOTAL } \\
\hline GERAÇÃODEENERGIA ELÉTRICA & 113,7 & 22,9 & 136,6 \\
\hline $\begin{array}{l}\text { TRANSMISSÃO DE ENERGIA } \\
\text { ELÉTRICA }\end{array}$ & 26,6 & 10,8 & 37,4 \\
\hline PETRÓLEO E GÁS NATURAL & 285,8 & 593,4 & 879,2 \\
\hline MARINHA MERCANTE & 36,7 & - & 36,7 \\
\hline COMBUSTÍVEIS RENOVÁVEIS & 1,0 & - & 1,0 \\
\hline EFICIÊNCIA ENERGÉTICA & 1,1 & - & 1,1 \\
\hline PESQUISA MINERAL & 0,6 & - & 0,6 \\
\hline TOTAL & 465,5 & 627,1 & $1.092,6$ \\
\hline
\end{tabular}

Fonte: MPI, 2010

Em relação ao Estado do Pará, conforme o documento oficial do $7 .^{\circ}$ Balanço do PAC II (de Jeneiro a Abril 2013), o investimento total previsto nesse estado é de R\$98, 74 bilhões, sendo: R \$ 45,94 bilhões entre 2011-2014 e R\$ 52,80 bilhões pós-2014. Quando comparado com o volume do PAC I, percebese um aumento significativo de investimento, sobretudo em infraestrutura, em especial na área de energia.

Em seu Relatório, 8. Balanço do PAC II, o governo federal destaca que, até agosto de 2013, foram investidos R $\$ 665$ bilhões em ações de infraestrutura, logística, além de projetos sociais e urbanos - 67,2\% do valor previsto até 2014 . 
Segundo o governo, o montante supera o aplicado durante a primeira fase do programa entre 2007 e 2010 PAC I (BRASIL, 2013) e sustenta “a retomada do planejamento no Brasil", assumindo o PAC a expressão de "programa estruturante do desenvolvimento do País" (BRASIL, 2013, p. 1).

Nesse resumido quadro panorâmico e esquemático do PAC I e II, é possível identificar um reposicionamento do Estado brasileiro na agenda e na dinâmica de desenvolvimento do país, por meio da orquestração desses grandes projetos, com foco prioritário em infraestrutura, em especial em energia. Nesse cenário e programa, a região amazônica é posta como dimensão territorial estratégica de ocupação e controle.

\subsection{APROVEITAMENTO HIDRELÉTRICO DE BELO MONTE COMO EXPRESSÃO DA EXPANSÃO DA FRONTEIRA HIDRELÉTRICA NA AMAZÔNIA}

Entre os vários megaprojetos e empreendimentos de infraestrutura do PAC destinados para a região amazônica, o Aproveitamento Hidrelétrico de Belo Monte ganha destaque e é apresentado pelo Governo Federal como um dos principais símbolos da nova era de "aceleração do crescimento" e de "desenvolvimento" do Brasil na atualidade, em particular da Amazônia. Esse megaempreendimento está situado no sudoeste do Estado do Pará, na Bacia do rio Xingu, em Vitória do Xingu, previsto para ser a terceira maior hidrelétrica do mundo (e a primeira totalmente nacional) com mais de $11.000 \mathrm{MW}$ de potência e com o maior investimento público do PAC. A previsão de iniciar o funcionamento e geração parcial de energia é em 2015, com sua motorização total prevista para janeiro de 2019 (EPE/MME, 2011). Tal empreendimento (como outros), contudo, tem sido alvo de diversas polêmicas (contra e a favor), gerando bastante tensões e conflitos. Essa polêmica tem tomado dimensão, além de local, regional e nacional, também internacional.

Ao fazer alusão ao Plano Decenal de Expansão de Energia-2021 da política energética do Estado Brasileiro, a Empresa de Pesquisa Energética (EPE) afirma:

O país contará com um acréscimo de 31,7 mil MW de geração hidrelétrica. A região Norte é onde ocorrerá a maior expansão hidrelétrica, devido à entrada em operação de grandes empreendimentos, com destaque para a usina hidrelétrica de Belo Monte, cuja motorização se dará em três anos com a entrada em operação de seis máquinas de 611,1 MW por ano (EPE/ MME, 2012, p. 3) ${ }^{1}$.

Em 2008, o Conselho Nacional de Política Energética (CNPE) aprovou a Resolução N. ${ }^{\circ} 06$ de 03 de julho de 2008, determinando que o governo federal não construa barragens adicionais a montante de Belo Monte na bacia hidrográfica do Xingu. 
A Empresa de Pesquisa Energética aponta, entre os grandes problemas do projeto anterior (do Complexo Hidrelétrico do Xingu da época do regime militar), a criação de um imenso reservatório e suas implicações sociais e ambientais para os povos e comunidades amazônidas do rio Xingu, como as indígenas da área da Volta Grande do Xingu e Paquiçamba. Além disso, assinala as fragilidades de viabilidade econômica e técnica (EPE/MME, 2011). Ao se referir à "evolução do atual projeto", a EPE destaca sua maior "eficiência e a proteção social e ambiental", através de medidas que "incluem uma redução da área alagada do reservatório de $1.225 \mathrm{~km}^{2}$ para $516 \mathrm{~km}^{2}$ " (EPE/MME, 2011, p. 2). Nesse sentido, a EPE concebe a reformulação do AHE Belo Monte como uma "abordagem inovadora" (EPE/MME, 2011, p. 3).

Salienta, ainda, que para assegurar as "condições de segurança, um vertedouro complementar será construído no sítio Bela Vista. Esse arranjo é complementado por um conjunto de diques para fechamento lateral de pontos baixos no reservatório dos canais" (EPE/MME, 2011, p. 3). No documento oficial, essa empresa, ao se reportar ao Projeto de AHE Belo Monte, enuncia os "Principais Fatos" que o marcam: "Projeto Nacional" "Parceira Público-Privada", "Desenvolvimento Sustentável"; e "Energia Limpa" (EPE/MME, 2011, p. 1). Em relação à compreensão de Belo Monte como "projeto nacional”, a Amazônia, em particular a Bacia do Xingu, é recolocada na política do Estado brasileiro como "projeto do planejamento energético", isto é, visando repor e reforçar o lugar da região como potencial hidrelétrico a ser explorado para prover a dinâmica de crescimento econômico e de desenvolvimento do país. No tocante à "parceira público-privada", o governo destaca a parceria com o Consórcio Norte Energia. No que se refere ao entendimento de Belo Monte, ele é sustentado como um projeto de "desenvolvimento sustentável" (EPE/MME, 2011, p. 1).

Ao se referir ao projeto de Belo Monte como exemplo de "energia limpa e renovável", o documento argumenta que "a hidrelétrica de Belo Monte ajudará a manter a posição atual do Brasil como uma das matrizes energéticas mais limpas de todos os países industrializados, com 46\% da energia proveniente de fontes renováveis (EPE/MME, 2011, p. 1). O Presidente da EPE, Maurício Tolmasquim (2010), destaca a diferença do atual projeto em relação ao anterior, argumentando que a nova versão não vai afetar "diretamente terras indígenas" e "reduz a área alagada". Sustenta, ainda, a viabilidade e garantia de geração de energia elétrica com "preservação ambiental" sem que seja necessário construir as outras cinco hidrelétricas no rio Xingu (TOLMASQUIM, 2010, p. 1).

Em um contraponto a essa matriz discursiva hegemônica, pesquisadores (as) de diversas instituições acadêmicas e científicas, membros do Ministério 
Público Federal, movimentos e organizações da sociedade civil, instituições não governamentais nacionais e internacionais passaram a contestar fortemente tal concepção, demarcando um campo de posição crítica ao referido projeto e ao modelo de desenvolvimento que ele encarna, inscrevendo, assim, uma arena de tensões e conflitos, que têm muito a revelar sobre os padrões de desenvolvimento em disputa na sociedade, em particular na Amazônia.

Conforme o Painel de Especialistas: Análise Crítica do Estudo de Impacto Ambiental do Aproveitamento Hidrelétrico de Belo Monte ${ }^{2}$, organizado pelos pesquisadores Sônia Magalhães, Francisco del Moral Hernández, Edna Castro, Nírvia Ravena e Rosa Acevedo (2009), o Estudo de Impacto Ambiental e o Relatório de Impacto Ambiental (EIA-Rima) sobre Belo Monte apresentam problemas de diversas ordens. Sobre os estudos, esse Painel identifica:

Inconsistência metodológica; ausência de referencial bibliográfico adequado e consistente; Ausência e falhas nos dados; Coleta e classificação assistemáticas de espécies, com riscos para o conhecimento e a preservação da biodiversidade local; Correlações que induzem ao erro e/ ou a interpretações duvidosas; Utilização de retórica para ocultamento de impactos (MAGALHÃES et al., 2009, p. 11)

Sobre os impactos, ele verifica:

Subdimensionamento da área diretamente afetada; Subdimensionamento da população atingida; Subdimensionamento da perda de biodiversidade; Subdimensionamento do deslocamento compulsório da população rural e urbana; Negação de impactos à jusante da barragem principal e da casa de força; Negligência na avaliação dos riscos à saúde; Negligência na avaliação dos riscos à segurança hídrica; Superdimensionamento da geração de energia; Subdimensionamento do custo social, ambiental e econômico da obra (MAGALHÃES et al., 2009, p. 11).

E enfatiza:

O Painel de Especialistas, sobretudo, chama atenção para a retórica sobre os impactos na Volta Grande, chamado - Trecho de Vazão Reduzida, que oculta, dentre outros, o fato de que Terras Indígenas - Juruna do Paquiçamba e Arara da Volta Grande - são "diretamente afetadas" pela obra. E, ademais, grupos Juruna, Arara, Xipaya, Kuruaya e Kayapó, que, imemorial e/ou tradicionalmente, habitam as margens deste trecho do Rio (MAGALHÃES et al., 2009, p. 11).

\footnotetext{
Esse Painel de Especialistas, segundo esse próprio documento, versa sobre "estudo crítico realizado por um Painel de Especialistas (pesquisadores de diversas instituições de ensino e pesquisa), com o objetivo de evidenciar para a sociedade as falhas, omissões e lacunas destes estudos e subsidiar um processo de decisão, que se espera seja pautado pelo debate público sério e democrático" (MAGALHÃES et al., 2009, p. 10). Esse estudo partiu de uma demanda de movimentos e organizações da sociedade civil, que protagonizam e lutam contra esses grandes empreendimentos, como Belo Monte e o modelo de desenvolvimento que ele representa.
} 
O Painel de Especialistas, ao tratar da "Área Diretamente Afetada", identifica que um conjunto de agricultores sofrerá com os impactos, tendo "suas terras parcialmente engolidas pela obra". No entanto, esse grupo social não foi considerado e reconhecido pelo EIA como inserido na área diretamente afetada, desconsiderando, assim, sua condição de "atingido" diretamente. "Conforme o EIA, foi deixado para avaliação posterior” (MAGALHÃES et al., 2009, p. 32). Nesse estudo, identifica-se, também, a "Ausência do detalhamento de programas e projetos de mitigação” (MAGALHÃES et al., 2009, p. 33).

Sevá Filho (2009, p. 3), que integra o Painel de Especialistas, identifica "uma manobra geográfica e jurídica". Ao colocar nesses termos, Sevá Filho se contrapõe ao argumento oficial de que somente Belo Monte será construída nessa Bacia do Xingu, assim como questiona a viabilidade do empreendimento, além dos problemas socioambientais que implica. Ao contrapor-se, também, ao discurso da "necessidade de se produzir energia a partir de hidrelétricas, consideradas erroneamente, aliás - como fontes limpas e renováveis", ele (2009, p. 4) verifica que "permanece em pleno vigor a ideia única de 'aproveitamento integral do potencial hidráulico' do rio Xingu" como "dogma central" do "fundamentalismo barrageiro". Ele, ainda, defende que a "área alagada não é de 400 e poucos km quadrados, pode ser 516 ou 605 km quadrados" (SEVÁ FILHO, 2009, p. 4).

Uma das principais polêmicas que cercam Belo Monte diz respeito à sua ineficiência energética, pois sua energia firme (média anual da energia a ser produzida) será inferior a $40 \%$ de sua potência, o que torna Belo Monte um dos empreendimentos hidrelétricos de menor eficiência energética do Brasil. No tocante a isso, Pinto (2011, p. 7), ao analisar o projeto anterior e comparar com as mudanças no projeto atual, adverte para o risco do funcionamento e da sua viabilidade econômica e energética.

Diante desse quadro, a decisão normativa do governo federal, através do Conselho Nacional de Política Energética (CNPE) de não construir outras hidrelétricas rio acima, revela-se ainda mais frágil e tende à construção de outras hidrelétricas como aponta Sevá Filho (2009) no "novo" inventário do desenho do Complexo Hidrelétrico do Xingu com quatro “eixos" hidrelétricos. Considerando, portanto, essa baixa vazão do rio Xingu durante quatro ou mais meses do ano, que tende a deixar ociosas as turbinas da casa de força principal, é grande a probabilidade em favor da construção dessas "novas" hidrelétricas, depois que Belo Monte se tornar um fato consumado. A construção de "novas hidrelétricas" rio acima, conforme alertam esses estudiosos, vai provocar elevados impactos e riscos sociais e ambientais, destacando-se conflitos com povos indígenas e comunidades tradicionais e camponesas e um aumento acentuado nas emissões de gases de efeito estufa. 
Tratando desse processo do ponto de vista jurídico, o Procurador da República no Estado do Pará, Felício Pontes Junior, identifica violações de direitos, em particular dos povos indígenas, posto desconsiderar-se a Constituição Federal e os Tratados Internacionais.

Tão grave quanto a falta da oitiva ${ }^{3}$ dos indígenas pelo Congresso é o argumento do governo exposto ao contestar uma das ações promovidas pelo Ministério Público Federal. Diz que não é necessária a oitiva porque nenhuma terra indígena será inundada. É verdade. Na Volta Grande do Xingu não haverá inundação. Haverá quase seca, já que a maior parte do rio vai ser desviado, levando ao desaparecimento de 273 espécies de peixes nos 100 quilômetros que passam em frente às Terras Indígenas Paquiçamba e Arara do Maia (PONTES JÚNIOR, 2011, p. 1).

Ao analisarem as mudanças recentes no Projeto de AHE Belo Monte, Hurwitz et al. (2011, p. 22) argumentam que "após a realização do leilão em abril de 2010, o Consórcio Norte Energia, com a finalidade de baratear custos de construção, alterou o projeto de engenharia de Belo Monte, o que resultou na manutenção de apenas um canal de derivação com 300 a 700m de largura e a retirada do vertedouro complementar". Hurwitz et al. (2011, p. 23) destacam que "não foram realizados estudos complementares sobre as conseqüências e os riscos sociais e ambientais associados a essa alteração do projeto de engenharia"4.

Esse modo de conceber o projeto de AHE Belo Monte evidencia e reforça o lugar reservado à região amazônica, em particular à Bacia do Xingu, como fronteira hidrelétrica (MAGALHÃES; HERNÁNDEZ, 2011) e como periferia da semiperiferia, haja vista sua inserção como potencial hidrelétrico a ser explorado e como exportadora de energia elétrica para prover "segurança energética", crescimento econômico e desenvolvimento capitalista ao país, sob uma perspectiva, marcadamente, neodesenvolvimentista. Isso revela um processo contraditório de territorialização da dinâmica hegemônica capitalista e

\footnotetext{
Explica o Procurador: "As audiências de licenciamento ambiental nada têm a ver com o instituto da oitiva das comunidades indígenas afetadas. Aquelas decorrem de qualquer processo de licenciamento ambiental de obras potencialmente poluidoras. Esta decorre do aproveitamento de recursos hídricos em terras indígenas. Aquelas são realizadas pelo órgão ambiental nos municípios afetados por uma obra. Esta, a oitiva, somente pelo Congresso Nacional (art. 231, $\$ 33^{\circ}$, da Constituição). Até hoje o Congresso Nacional jamais promoveu a oitiva das comunidades indígenas do Xingu. O processo legislativo para esse fim tramitou em 2005. Sua duração foi de menos de 15 dias na Câmara e no Senado. Um dos projetos mais rápidos de nossa recente história republicana. No dia de sua aprovação final, uns senadores, em sessão, o qualificaram de "projeto-bala" e "the flash". E nenhum indígena foi sequer ouvido. Ou seja, o Congresso simplesmente ignorou a legislação nacional e internacional e inventou um processo sem ouvir os indígenas" (PONTES JÚNIOR, 2011, p. 1).

4 É importante ressaltar que já existe estudo e solicitação de licenciamento para exploração de minério na região da Volta Grande do Xingu, em especial na área conhecida como de vazãa redurida, pela empresa canadense Belo Sun Mining Corp.
} 
colonialista, que reforça, nos termos de Santos (2006), um padrão de uma lógica de saber e de produção monocultural, colocando em cheque e invisibilizando outros saberes e experiências sociais de sociabilidade, que possam emergir desses povos e grupos sociais subalternos.

\section{AS LUTAS E RESISTÊNCIAS SOCIAIS DO MOVIMENTO XINGU VIVO PARA SEMPRE FRENTE AO PROJETO BELO MONTE}

Essa expansão da fronteira hidrelétrica no Brasil, em particular na região amazônica, através desses empreendimentos hidrelétricos, não vem se dando sem contradições e conflitos, sem lutas e resistências a esse modelo. Seguindo esses sinais e as pistas,é possível, também, capturar dinâmicas subterrâneas, não hegemônicas, a partir das resistências e lutas de movimentos e organizações sociais, que se dão nesse Brasil profundo e que ajudam a exprimir outras racionalidades e experiências sociais da Amazônia e do Brasil, que passam ao largo da interpretação hegemônica, visto que por esta são invisibilizadas e deslegitimadas numa correlação de poder estruturalmente assimétrica (SANTOS, 2006; ZHOURI, 2011; CASTRO, 2012).

Em decorrência de um conjunto de impactos socioambientais, provocado por esses empreendimentos hidrelétricos, produzem-se perdas materiais e simbólico-culturais. Essas são marcas e sinais da desterritorialização sofrida por povos e comunidades tradicionais e camponesas e por classes empobrecidas de cidades, que expressam a violação aos direitos humanos e aos ecossistemas. Como consequência, emergem lutas e resistências sociais plurais, em contextos históricos diferentes no país e na região, protagonizadas por ações coletivas e grupos sociais subalternos, que contestam esses empreendimentos e seu modelo de desenvolvimento e denunciam os graves problemas por eles vividos e enfrentados, inscrevendo, assim, dinâmicas múltiplas nesse campo de conflito socioambiental.

Em face desse quadro de risco de "desperdício de experiências e perspectivas" de representar o mundo e de construí-lo sob outros referenciais não hegemônicos (SANTOS, 2001; 2006), o que as lutas e resistências do Movimento Xingu Vivo Para Sempre (MXVPS) têm a revelar? Que pistas e sinais apontam? Na terceira fase dessa "batalha" contra o Projeto de Aproveitamento

\footnotetext{
No tocante às lutas e resistências sociais contra o referido empreendimento, é importante considerá-lo em perspectiva histórica. Um primeiro grande momento dessa "batalha" pode ser expresso em 1989 com o $1^{\circ}$ Encontro dos Povos Indígenas do Xingu, em Altamira, Estado do Pará, que resultou na suspensão e paralisação do Projeto Hidrelétrico Kararaô. Um outro grande momento foi em 2001, quando o projeto já reformulado, novamente, teve sua suspensão e
} 
Hidrelétrico Belo Monte um componente novo se impõe, o que vai provocar um forte "racha" e abalo no campo de resistência, que vinha se constituindo nessa região do Xingu e da Transamazônica e favorece, decididamente, a aprovação e implementação de Belo Monte ${ }^{6}$. Anteriormente, o projeto Kararaô e sua nova versão reformulada não estavam na agenda programática nem do PT nem do governo Lula, no início de seu mandato. No tocante à posição tomada pelo PT antes de assumir a presidência da República em 2003, uma liderança religiosa da região do Xingu e da Transamazônica, entrevistada por nós, destaca, em seu relato, que o referido partido e sua liderança nacional, Lula, se colocavam contra o projeto, compondo com os movimentos e organizações sociais da região um forte campo de resistência. Mas, com a chegada de Lula ao poder, o referido entrevistado realça a mudança de posição, gerando, para ele, "a primeira frustração sem tamanho!” (informação verbal) ${ }^{7}$.

Antônia Melo, liderança do Movimento de Mulheres e do MXVPS na região, relata o sentimento de "esperança de mudança" com a ascensão do PT e de Lula à presidência, mas, também, de decepção com a posição assumida em desengavetar o projeto de Belo Monte. Ela denuncia a retomada de grandes projetos para a região amazônica, em especial para o Xingu, associada e balizada por outras frentes econômicas de expansão da fronteira, expressas nos interesses de grandes empreendimentos minerometalúrgicos do capital internacional. Ademais, salienta a aliança com políticos e grupos de empreiteiras (grupo do PMDB, comandado

paralisação, por meio de uma Ação Civil Publica impetrada pelo Ministério Público Federal, que foi acionado por movimentos e organizações sociais da região do Xingu e da Transamazônica CASTRO, 2012). Cabe destacar o papel protagonista aqui do Movimento pela Sobrevivência na Transamazônica (MPST), que veio a se transformar em Movimento pelo Desenvolvimento da Transamazônica e do Xingu (MDTX). Um terceiro momento se dá em julho de 2005 com a aprovação do Decreto Legislativo, autorizando os estudos para a implantação do projeto de AHE Belo Monte, sem ouvir os povos indígenas, o que foi visto como um "duro golpe" à Constituição e à Convenção 169 da OIT, e consequentemente, aos direitos desses povos pelos movimentos e organizações sociais.

6 Vale ressaltar que, desde a década de 70 até meados da década de 80 , a igreja católica, através das CEBS, se apresentava como a principal agência de mediação na mobilização e organização dos movimentos socais e sindicais nessa região do Xingu e Transamazônica, a fim de lutar contra a ditadura, as classes e grupos dominantes e de levantar uma bandeira por direitos e justiça social. As CEBs, por meio da Teologia da Libertaşão, contribuíram para construção de um forte campo de resistência nessa região. No final da década de 80 e início de 90 , essa dinâmica, mobilização e articulação da sociedade civil passa a ser reconfigurada, sofrendo mudanças, ganhando maior amplitude, complexidade e diversidade com a emergência de novos setores e atores ou agentes sociais e temas, como as universidades públicas, por meio de seus cientistas/ intelectuais públicos ou "orgânicos"; ONGs (nacionais e internacionais) em defesa dos direitos indígenas e socioambientais, partidos políticos de esquerda, refazendo e estabelecendo, no processo democrático, uma nova relação de poder com o Estado, conformando novas configurações de forças sociais e políticas em apoio à luta e resistência de povos e comunidades tradicionais e de movimentos sociais do campo e da cidade. O PT assume papel importante como "intelectual coletivo" para levar a cabo tais demandas sociais e políticas.

JCXT. Entrevista. [jun. 2013]. Entrevistador: Sérgio Roberto Moraes Corrêa. 2013.

Novos Cadernos NAEA • v. 19 n. $3 \cdot$ p. 233-254 • set-dez 2016 
por Sarney, no controle do Ministério de Minas e Energia), que passam a compor um forte, heterogêneo e conflitante bloco hegemônico em defesa de uma política energética e de um modelo de desenvolvimento, com a retomada do papel do Estado em parceria com o capital privado nacional e transnacional, para a reprodução de acumulação capitalista e de elites políticas, com forte papel de setores e partidos do espectro da esquerda (MELO, 2005, p. 57).

Em Janeiro de 2007, o Governo Federal lança o PAC I, que passa a se constituir como um "divisor de águas" na agenda política estruturante do desenvolvimento do país, em particular para Amazônia, assumindo o AHE Belo Monte seu trunfo estratégico para aumento de sua capacidade de geração de energia e busca da continuidade de seu crescimento econômico. O "fogo" veio da "frente amiga" e a batalha ganha novos contornos e sentidos. Isso revela o "transformismo", nos termos de Gramsci (2011), pelo qual o P'T tem passado. Isso ajuda a compreender tanto o "racha", que veio a ocorrer no seio desse campo de lutas coletivas, como o enfraquecimento da resistência a Belo Monte e, por consequência, do esboço de projeto contra-hegemônico em construção, expondo uma fragmentação e forte fratura nesse campo de resistência.

Diante desse quadro de avanço do projeto, um novo ato de resistência e luta contra Belo Monte foi marcado pelo II Encontro dos Povos Indígenas e dos Movimentos Sociais, em 2008, denominado Xingu Vivo. Sobre esse encontro, uma liderança do MXVPS diz em que situação concreta e que condições levaram a sua realização:

Os indígenas, vendo que o governo avançava, que o governo Lula avançava, para implantar Belo Monte no Xingu, os indígenas convidaram, no início de 2008, os movimentos sociais da região, convidaram os agricultores, ribeirinhos, pescadores e os indígenas daqui do médio Xingu, para um grande encontro no modelo do encontro de 89. Eles queriam discutir o que era esse projeto Belo Monte, eles queriam saber porque o governo já estava implantando, e eles não tinham sido ouvidos, não tenham sido consultados, conforme diz a lei, e quanto mais os movimentos sociais! E aí nós trabalhamos articuladamente pra acontecer esse encontro em 2008 (informação verbal) ${ }^{8}$.

Um ativista do Comitê Metropolitano Xingu Vivo (CMXV), ao falar sobre a realização do II encontro e o surgimento desse Movimento Xingu Vivo Para Sempre, destaca seu objetivo e os adversários, que demarcam as correlações de poder.

DCMXV. Entrevista. [mar. 2012]. Entrevistador: Sérgio Roberto Moraes Corrêa. 2012. 
O objetivo final seria: a partir da somatória de forças, ter resultados melhores, visto que a luta contra a construção de Belo Monte é uma luta contra interesses que vêm de governo federal, governo estadual e governos municipais, empresas mineradoras e empreiteiras, políticos poderosos. Então, é uma luta contra poderes muito grandes! Um amigo diz assim: "essa luta contra belo monte é uma luta simplesmente contra o capital". Então, essa luta contra o capital é uma luta que requer muita luta e unidade, inclusive. Essa é uma concepção que faz com que essas organizações se juntem naquele momento (informação verbal) ${ }^{9}$.

Em relação ao MXVPS, ele é concebido como um "fórum de discussão e ação", que congrega mais de 250 organizações, segundo Monteiro (2012), uma de suas lideranças. Diferente do I Encontro dos Povos Indígenas do Xingu, em 1989, em que o próprio título evidencia o protagonismo eminentemente indígena, contando com o apoio dos movimentos e organizações da região, o II Encontro alarga e combina uma articulação entre Povos Indígenas e Movimentos Sociais, sendo possível verificar um protagonismo plural, que reflete uma aliança socioambiental e intercultural em construção e, também, uma rede de solidariedade nacional e internacional de apoio. Isso sugere perceber, nos termos de Boaventura Santos (2006), um movimento socioambiental e intercultural de resistência ativa emergindo do Sul e protagonizado pelos sujeitos do Sulcom a sua própria gramática amazônica expressa na defesa do "Xingu Vivo", como contraponto à sua morte, simbolizada por Belo Monte (ou "Belo Monstro", palavra de ordem cunhada pelo MXVPS) ${ }^{10}$, e ao modelo de desenvolvimento que ele expressa.

Ao falar sobre "as formas de atuação" do MXVPS, uma liderança do MXVPS, entrevistada por nós, destaca as suas "frentes de ação": a Frente jurídica atua identificando as ilegalidades da obra, assumindo importante papel a Sociedade em Defesa dos Direitos Humanos no Pará. Além dessa entidade, essa frente conta com a parceria do Ministério Público Federal e outras entidades internacionais em defesa dos direitos humanos; a Frente cientifica atua analisando tecnicamente o projeto (EIA-Rima) de Belo Monte e tem como principal parceiro o "Painel de Especialistas"; a Frente de comunicação atua divulgando o que ocorre em relação a Belo Monte, por meio do site do MXVPS, do blog do CMXV, das redes sociais e de seus jornalistas; e a Frente politica faz o trabalho de base, ajudando na mobilização e organização da luta contra Belo Monte. Esse mesmo ativista argumenta que tais frentes se articulam em uma agenda comum (informação verbal) ${ }^{11}$. Conforme essas informações, é apresentado um quadro da composição, estrutura e organização do MXVPS.

\footnotetext{
Idem.

10 Entre as várias palavras de ordem cunhadas pelo MXVPS a esse empreendimento, está "Belo Monte de Violência".

11 DCMXV. Entrevista. [mar. 2012]. Entrevistador: Sérgio Roberto Moraes Corrêa. 2012.
} 
Nesses termos, com a apresentação das frentes do MXVPS, é possível se identificar uma ação de resistência ativa, que combina e articula tanto diferentes agentes e agências sociais quanto diferentes dimensões e escalas da sociedade, revelando uma práxis política contra-hegemônica, que desenrola sua trama em diversas arenas ou campos de disputa em torno de Belo Monte, para problematizar o presente modelo de desenvolvimento e de sociedade. Nesse processo, o diálogo entre o MXVPS e a rede de agentes tem dado sinais de uma maior visibilização e reconfiguração do conflito, abarcando novos atores e territórios, reescrevendo a relação entre poder e saber, a luta política e a luta epistemológica, com vistas a manifestar e potencializar o debate público e a participação coletiva nos rumos da agenda da região e do Brasil. Essa dinâmica, todavia, tem se deparado e se confrontado com um forte contramovimento de esvaziamento do espaço público e diluição do dissenso, dificultando, assim, um debate aberto e participativo desses diversos atores nas questões centrais do país.

Um dos "golpes" considerados centrais para promover o "racha" e o consequente enfraquecimento da resistência contra Belo Monte foi a "cooptação" de lideranças indígenas da região da Volta Grande do Xingu, segundo vários depoimentos, através de repasse de dinheiro e outras coisas mais, como cestas básicas, carros, voadeiras etc. No tocante a isso, uma liderança religiosa da região, em entrevista a nós, diz que esse processo vem se dando em razão de, historicamente, esses povos estarem à margem do Estado, vivendo em condições precárias sociais e econômicas. Além disso, ele argumenta que dadas etnias já perderam, em grande medida, suas tradições e costumes, favorecendo ainda mais o convencimento e a cooptação para a aceitação de dinheiro e outras benesses, com o fim de passarem a defender o empreendimento de Belo Monte. Ele identifica a reintrodução do processo de "auricídio" com Belo Monte (informação verbal) ${ }^{12}$. Essa liderança religiosa cita algumas etnias dessa região que cederam ao empreendimento e um protesto dos Juruna que foi, rapidamente, acabado e desmontado com o repasse de dinheiro, "compra", pela Norte Energia (informação verbal) ${ }^{26}$.

Ele identifica uma "diferença" grande entre esses povos indígenas da Volta Grande do Xingu e os Kayapó (do Alto Xingu) e os Munduruku (da bacia do rio Tapajós). Em relação aos primeiros, ele argumenta que a sua tradição já se perdeu bastante e sua pauta prioritária é econômica (relação de troca); para os outros dois povos (Kayapó e Munduruku), a pauta é política, é a defesa de seus direitos, territórios, tradições e costumes, da conservação do meio ambiente (informação verbal) ${ }^{13}$.

12 JCXT. Entrevista. [jun. 2013]. Entrevistador: Sérgio Roberto Moraes Corrêa. 2013.

13 Idem. Aqui, é importante ressaltar que cada etnia indígena da Volta Grande do Xingu não 
Outro ponto é que o processo de “cooptação" desses povos indígenas desloca-os para outro campo de disputas, que são as condicionantes, a disputa pelos recursos. Esse foi um instrumento de cooptação e enfraquecimento do campo de resistência fundamental, pois deslocou o conflito, em grande medida, para o terreno das compensações e do imediatismo, sedimentando ainda mais a tensão entre os diversos grupos indígenas e não indígenas que disputam esses recursos, arrefecendo a luta contra Belo Monte e, consequentemente, enfraquecendo o MXVPS, que insiste na defesa contra o empreendimento. Nesse caso, com a retirada de cena de grande parte desses povos indígenas da Volta Grande, a ocupação dos canteiros de Belo Monte passa a ser protagonizada, em grande medida, pelos Munduruku, do território do Tapajós ${ }^{14}$. Esse é outro sinal importante da fratura e fragilização dessa resistência contra Belo Monte, mas, também, indica uma possibilidade de recomposição de forças com os povos do rio Tapajós, que estão defendendo o "Tapajós Vivo", como exemplo de aprendizado com o Xingu Vivo e o "Madeira Vivo".

Nesse campo de resistência, o que se identifica é que estão demarcadas posições e concepções diferentes e conflitantes quanto à organização e atuação diante do problema em pauta e da construção de alternativas, pondo como desafio a construção de um diálogo e unidade na diferença e no conflito, através de uma "rede de inteligibilidade", para reconstruir uma agenda coletiva e reposicionar esse campo de resistência contra-hegemônico.

\section{CONSIDERAÇÕES FINAIS}

É possível verificar um "campo de batalhas" que cerca esse projeto/ empreendimento de Belo Monte, um conjunto amplo e complexo de concepções, posições e polêmicas, que exprimem profundas tensões e conflitos. Belo Monte, como parte inerente do padrão de desenvolvimento hegemônico, recompõe um viés histórico desenvolvimentista, mas demonstra forte nexo com o mercado (nacional e transnacional), que avança sobre os recursos naturais, terras e territórios de povos e comunidades tradicionais e camponesas,

apresenta um posicionamento homogêneo em relação a Belo Monte, ainda que grandes grupos e caciques desses povos defendam o empreendimento. Por exemplo, a Jilma Xipaia, liderança de um pequeno grupo indígena Xipáia não é a favor de Belo Monte, mas a índia Maria Augusta, que representa grande parte dessa etnia defende o empreendimento. Outro exemplo é a liderança Sheila Juruna, que não defende o empreendimento, mas grande parte de seu povo defende. Portanto, é importante, também, considerar que há posicionamentos contrários e conflitantes entre esses grupos da Volta Grande.

14 Vale lembrar a onda de ocupações nos canteiros de Belo Monte em abril e maio de 2013. Assim como no começo de 2014. É importante destacar a ocupação do canteiro Belo Monte pelo Movimento Xingu Vivo, em 2012, durante o "Encontro Xingu + 23". 
com a forte presença e anuência do Estado brasileiro, injetando vultosos investimentos públicos e recodificando os marcos regulatórios, por meio de um processo de "flexibilização". Isso tem sido denunciado como exemplo de violações aos marcos legais e aos direitos humanos, para levar à frente esse padrão neodesenvolvimentista, que visa impulsionar seu crescimento à "luz" da reprimarização com as commodities, (re)introduzindo a Amazônia como uma fronteira em expansão, reproduzindo, assim, seu status de periferia da semiperiferia do capitalismo e do centro dominante capitalista e colonialista.

Diante dessas contradições concretas e simbólicas, essa expansão da fronteira hidrelétrica, tendo como símbolo o AHE Belo Monte, não vem, todavia, se processando sem lutas e resistências a esse empreendimento e ao modelo de desenvolvimento que ele encarna. É essa pista que procuramos seguir para demarcar que esse modelo neodesenvolvimentista é a expressão da (des-re) territorialização hegemônica, mas que as lutas e resistências a esse paradigma podem expressar experiências contra-hegemônicas de novas territorialidades (PORTO-GONÇALVES, 2001), isto é, de outras formas de sociabilidade, produzidas por baixo e por múltiplos sujeitos, trazendo à tona novas experiências sociais de resistência e de saberes (SANTOS, 2006).

Seguindo os sinais e as pistas das contradições e conflitos que esses empreendimentos e seu modelo neodesenvolvimentista produzem e expressam, é possível, também, capturar outras dinâmicas subterrâneas, não hegemônicas, a partir das resistências e lutas de movimentos e organizações sociais (SANTOS, 2006). Sob a perspectiva de Boaventura Santos (2001; 2006), essa problematização e desmistificação do discurso e do modelo hegemônicos ajudam a identificar experiências e perspectivas sociais invisibilizadas pela racionalidade "indolente" e pelo padrão capitalista e colonialista, a fim de vizibilizar novos saberes e representações sociais sobre essas questões energéticas e de desenvolvimento, demarcando a oportunidade de descolonizar a ciência a partir da periferia, da epistemologia do Sul. Nesse processo, é possível perceber uma renovação e complexificação da cartografia dos conflitos sociais.

\section{REFERÊNCIAS}

BRASIL. Balanço do PAC II (Maio/Agosto 2013). Brasília: Ministério do Planejamento, 2014. Disponível em: http://www.pac.gov.br/pub/up/relatorio/ c10686fbe8b91f0143eb5e80afea7985.pdfhttp:/ /www.planejamento.gov.br/ secretarias/upload/Arquivos/PAC2/131017_PAC_8_web.pdf. Acesso em: 15 mai. 2014. 
Balanço Regional do PAC II (Estado do Pará - Janeiro/Abril 2013). Brasília: Ministério do Planejamento, 2013. Disponível em: http://www.pac.gov.br/ pub/up/relatorio/c10686fbe8b91f0143eb5e80afea7985.pdf. Acesso em: 15 mai. 2014.

Programa de Aceleração do Crescimento (PAC II: 2011-2014). Brasília: Ministério do Planejamento, 2012a. Disponível em: http://www.brasil.gov.br/pac/. Acesso em: 27 jun. 2011.

Programa de Aceleração do Crescimento (PAC II: 2011-2014). Brasília: Ministério do Planejamento, 2012b. Disponível em: file://C:/Users/ Sergio/Downloads/PAC_2_-_Relat\%C3\%B3rio_do_lan\%C3\%A7amento_-_ mar\%C3\%A7o_2010_-_.pdf. Acesso em: 15 mai. 2014.

Lançamento da $2^{\mathrm{a}}$ Fase do Programa de Aceleração do Crescimento (PAC II). Brasília:Ministério do Planejamento, 2010.Disponívelem:file://C:/Users/ Sergio/Downloads/PAC_2_-_Relat\%C3\%B3rio_do_lan\%C3\%A7amento_-_ mar\%C3\%A7o_2010_-_\%20(2).pdf. Acesso em: 27 jun. 2011.

Programa de Aceleração do Crescimento (PAC): balanço 4 anos (2007-2010). Brasília: Ministério do Planejamento, 2010a. Disponível: http://www. planejamento.gov.br/secretarias/upload/Arquivos/noticias/pac/Pac_1_4.pdf. Acesso em: 15 mai. 2014.

Programa de Aceleração do Crescimento (PAC): balanço 4 anos (20072010). Brasília: Ministério do Planejamento, 2010b. Disponível: http://www.brasil. gov.br/pac/relatorios/nacionais/11o-balanco-4-anos/parte-1/view. Acesso em: 27 jun. 2011.

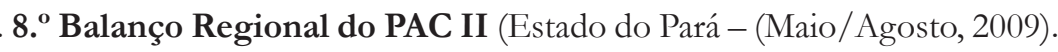
Brasília: Ministério do Planejamento. Disponível em: http://www.pac.gov.br/pub/ up/relatorio/babb30857acbd6a656e8225fdbd716d7.pdf. Acesso em: 28 jun. 2014.

Programa de Aceleração do Crescimento (PAC I: 2007-2010). Brasília: Ministério do Planejamento, 2007. Disponível em: http://www.brasil.gov.br/pac/ relatorios/nacionais/11o-balanco-4-anos/parte-1/view. Acesso em: 27 jun. 2011.

BRESSER-PEREIRA, L. C. O novo desenvolvimentismo e a ortodoxia convencional. São Paulo em Perspectiva. São Paulo: SEADE. v. 20, n. 3, p. 5-24, jul./set. 2006.

Retomada da revolução nacional e novo desenvolvimentismo. In: BRESSER-PEREIRA, Luiz C. Desenvolvimento e Crise no Brasil: História, Economia e Política de Getúlio Vargas a Lula. 5 ed. rev. São Paulo: Editora 34, 2003. CARNEIRO, R. Um Intelectual em seu labirinto. Carta Maior. Disponível em: http:/ /www.cartamaior.com.br/templates/colunaImprimir.cfm?coluna_id=5537. Acesso em: 03 abr. 2012. 
CASTRO, E. Expansão da fronteira, megaprojetos de Infraestrutura e integração sul-americana. Dossiê Amazônia. Caderno CRH, v. 25, n. 64, Salvador: Ed. UFBA, jan./abr. 2012.

CEPÊDA, V.. Inclusão, democracia e novo desenvolvimentismo: um balanço histórico. Revista de Estudos Avançados IEA- USP, n. 75. São Paulo: USP, 2012. EMPRESA DE PESQUISA Energética (EPE). Plano Decenal de Expansão de Energia 2020 / Ministério de Minas e Energia. Empresa de Pesquisa Energética. Brasília: MME/EPE, 2011. Disponível em: http:/ /www.mme.gov.br/mme/galerias/ arquivos/noticias/2011/RELATxRIO_PDE_2020.pdf.Acesso em: 16 mai. 2014.

Projeto da Usina Hidrelétrica de Belo Monte. Fatos e dados. Ministério de Minas e Energia/Empresa de Pesquisa Energética. Fevereiro - 2011. Disponível em: $\quad$ http://www.epe.gov.br/leiloes/Documents/Leil\%C3\%A3o\%20Belo\%20 Monte/Belo\%20Monte\%20-\%20Fatos\%20e\%20Dados\%20-\%20POR.pdf. Acesso em: 20 mai. 2014.

FIORI, J. L. O “desenvolvimentismo de esquerda". Carta Maior: Debate Aberto. Disponível em: http://www.cartamaior.com.br/templates/colunaMostrar. cfm?coluna_id=5495\&boletim_id=1140\&componente_id=18221. Acesso em: 3 mar. 2012.

“A miséria do "novo desenvolvimentismo”. Carta Maior: Disponível em: http://www.cartamaior.com.br/templates/colunaImprimir.cfm?coluna_id=5334. Acesso em: 30 nov. 2011.

GRAMSCI, A. Cadernos do Cárcere, v.3: Maquiavel: notas sobre o Estado e a política. Rio de Janeiro: Civilização Brasileira, 2011.

HURWITZ, Z. et al. Mega-Projeto, Mega-Riscos. São Paulo: Amigos da Terra/ Amazônia Brasileira/ International Rivers, 2011.

MAGALHÃES, S.; HERNÁNDEZ, F.. Ciência, Cientistas, Democracia Desfigurada e Licenciamento Ambiental sob Constrangimento. In: ZHOURI, Andréa. (Org.). As tensões do lugar: hidrelétricas, sujeitos e licenciamento ambiental. Belo Horizonte: Ed. UFMG, 2011.

Painel de Especialistas: Análise Crítica do Estudo de Impacto Ambiental do Aproveitamento Hidrelétrico de Belo Monte, 2009.

MELO, A. O assédio da Eletronorte sobre o povo e as entidades na região de Altamira. In: SEVÁ FILHO, A. Oswaldo. (Org.). Tenotã-Mõ: Alertas sobre as conseqüências dos projetos hidrelétricos no rio Xingu. São Paulo: IRN (International Rivers Network), 2005. 
MONTEIRO, D. (Entrevista). Opinião Socialista. Disponível em: http:// somostodosedmilson.blogspot.com.br/2011/04/opiniao-dion-monteiro-belomonte-e.html. Acesso em: 9 jun. 2012.

PINTO, L. F. Belo Monte confirma a energia da colônia. Jornal Pessoal: A agenda amazônica de Lúcio Flávio Pinto. Ano XXIV. N491. 2a quinzena de Junho, 2011.

PONTES JÚNIOR, F. Belo Monte e o último ritual indígena. Movimento Xingu Vivo para Sempre. Altamira, 19/04/2011. Disponível em: http://www.xinguvivo. org.br/2011/04/19/belo-monte-e-o-ultimo-ritual-indigena/

PORTO-GONÇALVES, C. W. - Da geografia às geo-grafias: um mundo em busca de novas territorialidades. CLACSO, 2001. Disponivel em: bibliotecavirtual. clacso.org.ar/ar/libros/cecena/porto.pdf

RIDENTI, M. Vinte anos após a queda do muro: a reencarnação do desenvolvimentismo no Brasil. REVISTA USP. n.84. São Paulo: dezembro/ fevereiro 2009-2010.

. Desenvolvimentismo: o retorno. Revista Espaço Acadêmico. n. 92, janeiro de 2009. Disponível em: http://www.espacoacademico.com.br/092/92ridenti.pdf. Acesso em: 16 mai. 2014.

SANTOS, B. A gramática do tempo: para uma nova cultura política. São Paulo: Cortez, 2006.

A crítica da Razão Indolente: contra o desperdício da experiência. São Paulo: Cortez, 2001.

SEVÁ FILHO, A. O. BELO MONTE de mentiras: Trinta anos de manobras estranhas, omissão de informações cruciais e algumas mentiras grossas. Disponível no site do Movimento Xingu Vivo Para Sempre, 2009.

SICSÚ, J. et al. Por que novo-desenvolvimentismo? Revista de Economia Política. v. 4, n. 27, 2007.

TOLMASQUIM, M. Belo Monte não sairia do papel sem governo. Reuters/Brasil Online. Disponível em: http://oglobo.globo.com/economia/mat/2010/07/27/ tolmasquim-belo-monte-nao-sairia-do-papel-sem-governo-917252267.asp. Acesso em: 13 mai. 2014.

ZHOURI, A. Introdução. As tensões dolugar: hidrelétricas, sujeitos e licenciamento ambiental. In: ZHOURI, Andréa (Org.). Belo Horizonte: Ed. UFMG, 2011. 